\title{
Experiences of Returning Korean-Chinese Students: The Sociocultural and Psychological Racism Perspectives
}

\author{
Luis Miguel Dos Santos
}

\author{
Assistant Professor, \\ Woosong University, Daejeon 34514, \\ South Korea
}

DOI: https://doi.org/10.36941/ajis-2022-0032

\begin{abstract}
The South Korean government encourages the Korean diaspora members to return to South Korea for personal and career developments. Many Korean-Chinese students decided to come back to their homeland for education and further career pathways. However, many Korean-Chinese face challenges and difficulties in South Korean schools and communities due to social and cultural differences. This study aims to understand the challenges of Korean-Chinese university students. Two research questions guided this study, including 1) how would Korean-Chinese university students describe their experiences based on the Sociocultural and Psychological Racism perspective during their university voyage in South Korea and 2) do Korean-Chinese university students face any particular difficulties and challenges due to their Korean-Chinese status based on the Sociocultural and Psychological Racism perspective during their university voyage in South Korea. Interview sessions and focus group activities were employed to collect data from 30 participants across the Korean peninsula. The results indicated that cultural characteristics, place of origin, and spoken languages are the three challenges for all Korean-Chinese participants. The results of this study filled the gaps in returning Korean students' experiences, challenges and difficulties. Also, government leaders may reform and polish the current policies in order to help other Korean diaspora in the South Korean communities.
\end{abstract}

Keywords: Korean-Chinese, Korean diaspora, overseas Korean, Returning Korean, sociocultural and psychological racism

\section{Introduction}

\subsection{Background}

South Korea is a popular educational destination, particularly regarding higher education, for international students from all over the globe (Song \& Bae, 2018). Although the international-student population and percentage in South Korea are not as high as in other countries and regions, such as the United States, the United Kingdom, Canada, Australia, and New Zealand (Castillo Arredondo et al., 2018), South Korea attracts many students due to recent developments in popular culture and the sciences. Aside from international students without any prior background or heritage from the Korean Peninsula, some are members of a special group of the Korean diaspora called Korean-Chinese currently living in mainland China due to the Korean War of the mid-20 ${ }^{\text {th }}$ century (Gao, 2012). 
During the last century, a large group of Korean nationals, mainly North Koreans, left the Korean Peninsula for mainland China due to the Korean War. According to the most recent statistics from the National Ethnic Affairs Commission of the People's Republic of China (2010), over 1.8 million Korean-Chinese residents (i.e., Joseonjok or Chosonjok or 朝鮮族) live in the northeastern provinces of China, including Jilin Province (吉林省), Heilongjiang Province (黑龍江省), and Liaoning Province (遼寧省). Specifically, over 1.1 million people live in Jilin Province, nearly 400 thousand people live in Heilongjiang Province, and 24 thousand people live in Liaoning Province. Due to the economic development of many Chinese communities, some people (Korean-Chinese residents) are moving to other regions and cities. Still, most Korean-Chinese residents stay in their original places and towns (in China) for further developments (Chosonjok, 2021).

Within the past two decades, the South Korean government announced a special programme for overseas Korean people without South Korean citizenship to return to South Korea. The programme is called the F-4 Overseas Korean Visa programme (재 외 동 포 or 在外同胞). Ethnic Korean people must meet one of the following criteria for this Visa, including an overseas Korean National (Kyopo or 교 포 or 僑胞), an individual who used to have Korean citizenship, an individual who immigrated to their current home country of citizenship before 1948, an individual who was born in an overseas country and has that country's citizenship, a foreign citizen (Lee \& Chien, 2017). One of the most commonly met requirements to apply for this F-4 Overseas Korean Visa is to be a foreign citizen with at least one parent or grandparent who was a Korean citizen in the past.

In this case, Korean-Chinese residents holding Chinese citizenship with evidence of Korean family heritage are eligible for this F-4 Overseas Korean Visa programme (as the South Korean government has always considered them part of the South Korean community) (Chung, 2020). As a result, in 2010, nearly 130,000 visa applications were approved. In 2013, over 280,000 individuals applied and received their F-4 Visa, while over 515,00o individuals received their F-4 Visa in 2017. In other words, in 2017, the South Korean government issued more than four times the number of F-4 Visas than in the starting year of 2010 (Korea Immigration Service Statistics 2017, 2017).

A previous study (Seol \& Skrentny, 2009) indicated that Korean-Chinese people formed the largest foreign population in South Korea (i.e. 237,000 in 2006, compared to only 145,00o Chinese people). Although these Korean-Chinese people have the right to work and study in South Korea for personal, academic, career, and financial development, their personal background and status (i.e., Korean-Chinese of Korean heritage) limit their opportunities. For example, the researcher categorised the Korean-Chinese population into three groups, 1) including migrant workers and job-seekers (i.e. usually blue-collar workers), 2) spouses of other South Korean citizens, and 3) students and shortterm visitors (Seol \& Skrentny, 2009). It is worth noting that South Korean citizens generally do not consider Korean-Chinese residents as South Korean as they hold a foreign passport (were not originally born in South Korea).

Discrimination based on nationality and visa status is a long-term political and social problem in South Korea (Dos Santos, 2020; Dos Santos, 2020a, 2020b). Discrimination may happen at different levels (e.g. at the individual, institutional, and structural levels) and may cause stress and burnout over a person's lifespan (Williams, 1999). A recent study (Hong, 2019) indicated that the foreign population in South Korea, (e.g. both workers and students who face discrimination and unfairness), usually live under health and mental disorders. Based on these findings, Hong (2019) argued that the Korean-Chinese population faces discrimination and mental health issues due to their cultural heritage (i.e., Korean-Chinese heritage). Although Korean-Chinese people strongly believe in their Korean heritage and nationality, local South Korean communities do not recognise and thus ignore their social status and nationality as (South) Koreans.

Some other studies (Kim, 2015; Lee, 1997) also investigated the Korean-Chinese population's problems in South Korea. During the 1990s, the government announced a foreign worker visa scheme (i.e. the Industrial Technical Training Programme), which allowed the immigration of blue-collar workers for dirty, difficult, and dangerous occupations. Although Korean-Chinese people were 
allowed to work and study in South Korea, both government agencies and the general public advocated that the Industrial Technical Training Programme was exclusively designed for the Korean-Chinese and undocumented population(s) to work in blue-collar industries. Although some Korean-Chinese residents completed their vocational educational training, secondary school diplomas, and even university qualifications, the local South Korean general public members still viewed and considered them as blue-collar workers, regardless of their qualifications and skilled backgrounds (Seol \& Skrentny, 2009). In other words, social status was determined by an individual's nationality and place of origin instead of their qualifications and abilities.

\subsection{Purpose of the Study}

This study aims to understand Korean-Chinese university students' experiences and lived stories based on the Sociocultural and Psychological Racism theory (Dos Santos, 2019, 2020; Lee et al., 2017; Lee, 2007). Based on the previous literature, Korean-Chinese residents are among the one of the largest (foreign) groups in the South Korean communities. It is important to understand their experiences in South Korean communities, particularly those of Korean-Chinese students during their university voyage. Although Korean-Chinese students live in South Korea as overseas Korean residents with permanent residency, they are still considered Chinese citizens by law. Also, many of these people come to South Korea to attend senior high school or university during their late teens.

Furthermore, many Korean-Chinese people may speak fluent Korean language due to the special (minority) curriculum in mainland China. However, the applications and uses of the Korean language tend to be traditional (i.e. old-fashioned) Korean. Therefore, Korean-Chinese university students may face challenges and difficulties during their university voyage in South Korea based on nationality, place of origin, spoken language, and social behaviours. Based on the abovementioned challenges and difficulties, the current study was guided by two research questions in order to solve and answer the problems, as the following,

1. How would Korean-Chinese university students describe their experiences based on the Sociocultural and Psychological Racism theory during their university voyage in South Korea?

2. Do Korean-Chinese university students face any particular difficulties and challenges due to their Korean-Chinese status based on the Sociocultural and Psychological Racism theory during their university voyage in South Korea? If so, why and how?

\subsection{Significance of the Study}

Like with many diasporas, the self-identity of Korean diaspora members is significant. In other words, although Korean diaspora members do not live in their homeland (i.e. they have non-Korean nationality), many continue to teach Korean culture, language, and social practices to the next generations to establish connections with Korea (Fang, 2009). In order to build up the connection of future generations with Korea, Korean people in China established Korean bilingual schools and programmes (Gao, 2010). Many Korean-Chinese people express their willingness to return to the Korean Peninsula for personal, academic, and career development as Korean people at some points in their lives (Gao, 2012). Based on the policy of the South Korean government, many Chinese-Korean individuals decided to come back to their homeland (i.e. the Korean Peninsula) for development.

In this case, the participants (i.e., Korean-Chinese individuals) decided to return to South Korea for university education and potential career development (potentially after graduation). The results of this study highlight the experiences, difficulties, and challenges from the perspectives of KoreanChinese individuals in South Korea. More importantly, the results of this study will provide ideas to the South Korean government on how to reform current policies regarding overseas Koreans and Korean diaspora members who want to come back to the Korean Peninsula for development. 


\subsection{Theoretical Framework: Sociocultural and Psychological Racism Perspective}

The researcher employed the Sociocultural and Psychological Racism theory (Dos Santos, 2019, 2020; Lee et al., 2017; Lee, 2007) as the theoretical framework of this study. Unlike the traditional theories about racism (i.e. discrimination based on skin colour and race), the Sociocultural and Psychological Racism theory advocates that individuals would be discriminated against based on two directions (Dos Santos, 2021). First, the psychological and internal factors include religious and philosophical behaviours and personal beliefs. Second, the social, personal, and external factors include place of origin, age, social behaviours, cultural characteristics, sexual orientation, and career development (Dos Santos, 2019, 2020; Lee et al., 2017; Lee, 2007).

The Sociocultural and Psychological Racism theory was developed based on the development of the Neo-Racism theory by Lee and her co-workers (Dos Santos, 2019, 2020; Lee et al., 2017; Lee, 2007). The theory indicated that people with the same skin colour and race might be discriminated against based on other non-traditional characteristics. In her studies, Chinese people were discriminated against in South Korea, although Chinese people share the same skin colour and race as South Korean people.

However, due to the social developments and the complex society, a researcher (Dos Santos, 2020; Dos Santos, 2019) developed the current Sociocultural and Psychological Racism theory (Dos Santos, 2019, 2020; Lee et al., 2017; Lee, 2007) as the enhanced approach. For the application in this study, the researcher employed the Sociocultural and Psychological Racism theory (Dos Santos, 2019, 2020; Lee et al., 2017; Lee, 2007) as the theoretical framework to understand the challenges and issues of Korean-Chinese who are considered as the Korean diaspora members of the Korean peninsula. Please see Figure 1 for the Sociocultural and Psychological Racism theory (Dos Santos, 2019, 2020; Lee et al., 2017; Lee, 2007).

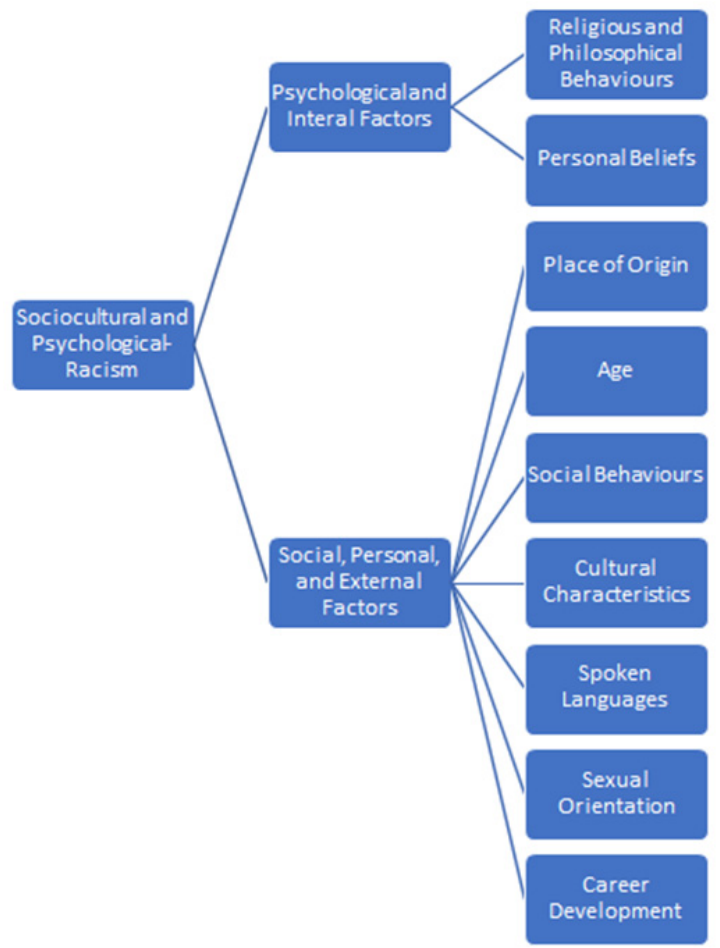

Figure 1: Sociocultural and Psychological Racism theory (Dos Santos, 2019, 2020; Lee et al., 2017; Lee, 2007) 


\section{Materials and Methods}

\subsection{The Qualitative Research Design: Phenomenological Approach}

The phenomenological approach (Giorgi, 1985) was employed in this study. This approach was employed because the researcher wants to understand the comments and opinions from KoreanChinese university students' perspectives from a wider angle. Unlike other qualitative designs, such as case study, the studies with a phenomenological approach may capture qualitative data from a larger population in the country or region. The populations do not limit to a particular site or location. As a result, the results of the study may better represent the population in the country or region.

\subsection{Recruitment and Participants}

The snowball sampling strategy (Creswell, 2014; Merriam, 2009) was employed to recruit 30 participants. First of all, the researcher contacted three potential participants. After the participants verbally agreed with the arrangement, the researcher sent the agreement, interview protocol, and related materials as the invitation. Three agreed with the participation.

Second, after the participants completed the interview procedure(s), each should refer at least one potential participant for further development. As a result, 30 participants joined the study. As the rationale of this study is to understand the university and social experiences and challenges of Korean-Chinese students in South Korea, the participants should meet all of the following,

Identify as a Korean-Chinese;

Currently enrolled as a student at a South Korean university;

Stay in South Korea for at least one academic year;

At least 18 years old;

Non-Vulnerable person.

\subsection{Data Collection}

Three tools were employed for the data collection (i.e. interview sessions, focus group activities, and member checking interview sessions). First, based on the agreement (i.e. consent form), all participants should complete two interview sessions. The interview sessions were one-on-one and private sessions with open-ended and semi-structured questions. Due to the recommendation of the social distancing because the COVID-19 pandemic, the participants could request the distance-based interview session in order to protect their health. Therefore, both face-to-face (four sessions) and distance-based ( 56 sessions) interview sessions were employed. Each interview session lasted from 61 to 86 minutes.

Second, after the researcher completed all of the interview sessions (i.e. 6o interview sessions), the researcher invited all participants for the focus group activities. Due to the government policies, face-to-face discussion groups were highly discouraged. Therefore, distance-based focus group activities were conducted. For the focus group activities, six people joined into a single focus group activity. In other words, five groups were formed for the data collection procedure. Each focus group activity lasted from 82 to 119 minutes.

Third, after the researcher categorised the data based on each participant, the researcher sent the related materials to each appropriate participant for the member checking interview and confirmation. The member checking interview sessions were conducted via the distance-based tool. Each member checking interview lasted from 20 to 34 minutes. All participants agreed and confirmed their materials. 


\subsection{The Use of Language}

The mother tongue of these groups of participants was the Korean language. Due to the geographic and early childhood experiences in mainland China, all participants were multi-lingual in Korean, Chinese, and English. However, as English is their third language, some participants could not express their ideas and comments fluently. Therefore, the researcher allowed the participants to share their stories in Mandarin Chinese and English. Written Korean messages were welcome as well. As a result, all participants expressed their sharing in Mandarin Chinese and English. No Korean stories were captured.

\subsection{Data Analysis}

The grounded theory approach (Strauss \& Corbin, 1990) for data analysis was employed. The researcher translated the sharing from Mandarin Chinese to English for the data analysis. The researcher transcribed the voiced messages to written transcripts for this study. After the researcher categorised the materials into different orders, the researcher re-read the written materials multiple times for the groups and themes.

The researcher first employed the open-coding technique (Strauss \& Corbin, 1990) for any potential themes and subthemes. The researcher yielded 18 themes and 22 subthemes as the firstlevel themes for this procedure. However, qualitative researchers (Merriam, 2009; Tang \& Dos Santos, 2017) advocated that further developments were needed. Therefore, the axial-coding technique was employed. As a result, four themes and three subthemes were merged.

\subsection{Human Subject Protection}

Privacy for all parties is the most important element in this study. All the signed agreements, personal contacts, email addresses, voiced messages, written transcripts, computer, and related materials were locked in a password-protected cabinet. Only the researcher could read the materials. After the researcher completed the study, all related materials were deleted and destroyed for personal privacy. The current study was supported by the Woosong University Academic Research Funding 2022.

\section{Results and Discussions}

Based on the comments and opinions of the participants, all expressed negative lived stories, cases of discrimination and bias, and difficulties from the South Korean communities. Although the participants were living in different parts of South Korea, including urban, suburban, and rural communities, all shared similar cases regardless of location. After the data analysis procedure, the researcher categorised four themes and three subthemes based on the Sociocultural and Psychological Racism theory (Dos Santos, 2019, 2020; Lee et al., 2017; Lee, 2007). Table 1 outlines the themes and subthemes.

Table 1: Themes and subthemes

\begin{tabular}{|l|}
\hline \multicolumn{1}{|l|}{ Themes and Subthemes } \\
\hline I am a Korean but am Discriminated by my Own People: The Sin of my Nationality \\
\hline I am discriminated against because I was not born in Korea \\
\hline I Speak the Textbook Korean Language: The Old and North Korean-Oriented Language \\
\hline Social Behaviours: I cannot Have my Own Hobbies \\
\hline I have adopted the South Korean living style, but the discrimination continues \\
\hline I do not Practice South Korean Traditions and Cultural Heritage \\
\hline It is my sin to celebrate Chinese festivals but not South Korean ones \\
\hline
\end{tabular}




\subsection{I am a Korean but am Discriminated by my Own People: The Sin of my Nationality}

\subsubsection{I am Discriminated against because I Was not Born in Korea}

I was so happy to come back to our homeland...for education and job after university...but I was wrong...although all my families are Korean...my birthplace always limited my opportunities, my friendship, my education, and even the ways...that I want to survive in this land...I used to believe I am a Korean because of my heritage...but none of them called me Korean but a Chinese...a Chinese person who wants to take advantage from the Korean society... (Participant \#30, Interview)

The researcher asked each participant about their self-identity and sense-of-belonging, particularly regarding their understanding and perspectives before returning to South Korea for university education, at the beginning of the interview session. All of them advocated that they were both Chinese and Korean (regardless of the political issues between North and South Korea). All believed that China was their birthplace and the Korean Peninsula was their place of origin or the root of their heritage (Gao, 2010). As one participant said,

...I am Chinese because I was born in China...but I was born in a Korean family...my parents and four grandparents were from the Korean Peninsula...we are Korean but living in China...because of political issues...I enjoyed in unique background and heritage... (Participant \#21, Interview)

All participants shared similar comments because of their Korean-Chinese heritage and relationship. Many seemed to enjoy their identities as minorities in China and special overseas Korean people in South Korea (Zhao, 2010). However, when the researcher further asked about their experiences as Korean-Chinese or overseas Korean residents in the South Korean social and university environments, all expressed negative and extreme cases and lived stories due to their nationality and residency.

First, all 30 participants expressed experiences of discrimination due to their birthplace or place of origin. It is worth noting that all participants shared the same skin colour and racial identification as the general public members in South Korea. Without further examination, it would have been impossible to identify the differences between the two parties based on outlook and facial characteristics. However, South Korean people always asked the participants about their place of origin (i.e., where the participants were originally from). The researcher captured two messages,

...where are you from? ... are you from the countryside?... why are you here in the big city?...many Korean people ask me these questions...I think it is very impolite...I told them I am from the Korean Peninsula...this is my homeland...but they always want me to tell them...my birthplace is in China...I am an overseas Korean...I have my rights...to refuse the answers...but they keep asking...until you told them...(Participant \#18, Focus Group Activity)

...Is your hometown in Seoul...in Busan...in Daejeon...in Daegu...in Gwangju...in Incheon? ...you must be a pig from the countryside...they called me a pig because they knew I was not born in South Korea...some classmates asked me these questions...and they can identify...because of my name is in Chinese Pinyin [oral spelling system]...although I always identify myself...as Korean...because I am really a Korean...but those Korean people...just want to make fun...of my unique background...(Participant \#11, Focus Group Activity)

The participants kept saying that once the South Korean people (i.e. members of the general public and classmates) identified them as Korean-Chinese, some of them always made fun of their unique background and cultural heritage (Zhao, 2010). Although some participants refused to answer, the discrimination and verbal harassment negatively affected their positive experiences in South Korea.

Second, nearly all experienced negative cases and discrimination because of their birthplace 
(i.e., mainland China). One of the requirements for the F-4 Visa is to have at least one Korean parent or grandparent. Based on the Jus Sanguinis or the right of blood, the participants may gain their permanent residency and citizenship after they meet the requirements. In other words, they are Korean diaspora members (Cui \& Zheng, 2021). In this case, all participants expressed that they were asked to share their nationality at least five times per year in general and official communications in school, government offices, and the general community. Several commented,

...I don't understand why...they need to seek the real answers for a general chat...I don't feel good with this personal and sensitive information...I refused...to answer...they called me selfish...isolated person....bored person...look down people because of my unique background... (Participant \#10, Focus Group Activity)

...The school international office staff asked me...what is my Visa type...F-4 the overseas Korean people...but they called me to Chinese people with the F-4 Visa...but not the overseas Korean...I told them Korea is my homeland...but they sought...me to say my homeland is China...not Korea...I felt unhappy and angry... why do they ask... all the time... (Participant \#2, Interview)

...the immigration officers always asked me...why are you stay in Korea...when will you go back to China...you should stay in Korea for some good purposes...but take away the funds from the Korean communities...when I go to the government offices or immigration...these statements and sentences...made me sick... (Participant \#28, Focus Group Activity)

The curiosity of members of the general public and the lack of acceptance from officials significantly reduced the positive experiences of these participants. Although some scholars (Hong et al., 2017) indicate that Korean people like to understand people's background to allow in-depth friendship and social interactions, the participants did not feel comfortable with the curiosity regarding their nationality and place of origin. More importantly, the participants believed this curiosity was a form of discrimination and bias based on the Sociocultural and Psychological Racism theory (Dos Santos, 2019, 2020; Lee et al., 2017; Lee, 2007).

\subsection{Speak the Textbook Korean Languages: The Old and North-Korean-Oriented Language}

...they all me old Korean or grandmother in my soul...I don't feel positive...because they laugh at my language application...as a Korean...using old-schooled languages... what is my wrong? (Participant \#5, Focus Group Activity)

Like many other languages, the differences between written and spoken Korean languages may increase difficulty and confusion for native and non-native speakers (Liao \& Yang, 2012; Sun et al., 2016). According to a previous study (Gao, 2010), Korean-Chinese residents usually learn Korean from family members, school teachers, and textbook materials. Due to political and geographic issues, although the participants learnt Korean languages from their school environments, their applications and lexical sets were not the same as those of South Korean speakers (Cui \& Zheng, 2021). One said,

...many of the South Korean languages...have many English and foreign languages...vocabulary and metaphors...we do not have these metaphors...from our textbooks back in mainland China...for example, shampoo, chicken, burger, cell phone...these are all from foreign languages... (Participant \#8, Focus Group Activity)

Although South Korea is a small region, people from different provinces speak their own Korean language with local accents and vocabulary (Min, 2020). According to a recent study (Park, 2020), Seoul has become the political and economic centre of South Korea due to government control and management. As a result, Seoul's sociocultural impacts and language applications have become the standardised images for all South Koreans. As South Korean people tend to discriminate against provincial (e.g., countryside and rural communities) people born in South Korea, it is not surprising 
that Korean-Chinese people experience the same issues. As two said,

...I learnt my Korean language from the textbook...my parents...my grandparents...my teachers and classmates...I don't think it was a problem...but when I arrived in South Korea...people laughed at me because my language...is too textbook-style...I really don't know why...they have to laugh at me...you can say I am old-fashioned...but why laugh and discriminate? (Participant \#17, Interview)

...people called me North Korean spy because I speak the North Korean language...my Korean is not from the North...my Korean is from the textbook...the book is old...my grandparents are old...but it doesn't mean that I am a North Korean spy... (Participant \#3, Focus Group Activity)

In conclusion, based on a recent study (Cui \& Zheng, 2021), the relationships and connections of Korean-Chinese people to South Korea mainly focus on bloodlines and family heritage(s). However, their languages and sociocultural behaviours are not significantly similar as these two groups of people have grown up in different places (Lyu, 2020). Although bloodlines and heritage(s) connected them, the general public and local communities did not accept the participants' arrival, as South Korean people like to compare people based on their personal characteristics, social behaviours, cultural heritage, and family background. As a result, reflecting the Sociocultural and Psychological Racism theory (Dos Santos, 2019, 2020; Lee et al., 2017; Lee, 2007), the participants expressed negative experiences due to their differences with the local South Korean people.

\subsection{Social Behaviours: I cannot Have my Own Hobbies}

Another difficulty that the participants faced was their selection(s) of personal hobbies. Unlike western societies, where individuals have their own perspectives and respect for self-identity is highly regarded (Campion \& Wang, 2019; Han, 2017), in the East Asian region, the ideas of the group and collectivism are the dominant social trend. All people should follow similar hobbies and social behaviours to show respectfulness to each other (Han, 2017; Li et al., 2018). Although the participants understood and experienced these social behaviours and expectations as they grew up in mainland China as minorities, many were allowed to select their hobbies, interests, and activities based on their personal interests. However, all 30 expressed concern(s) about their freedom of selection(s) in South Korea. In particular, they explained that they had to express their interest in Korean pop music and TV dramas. All 30 expressed negative experiences of discrimination and bias due to them not liking Korean singers and TV drama stars. The researcher captured some comments,

...I really don't like the Korean singers...I came to Korea for university...and for my return...back to my homeland...I am not here for the pop culture and drama...some classmates and the general public...asked me about my intention of Korean singers and TV drama...I told them I have no interests...but they forced me to love Korean singers...otherwise, I am not a Korean... (Participant \#15, Focus Group Activity)

I like Korea...it is my homeland...but I don't like to pop culture...because I don't like music or what...I want to focus on education and my university project...I don't go to any concerts...but my classmates and friends...told me that if I don't like Korean songs...how can I become a Korean...I felt so unhappy because of these types of questions and answers... (Participant \#26, Interview)

Besides ideas about Korean pop culture, such as music and TV dramas, almost all expressed that their Korean friends needed them to like Korean sports teams (i.e., they could not support Chinese sports teams). These forced ideas from their Korean friends highly reduced their satisfaction(s). Two comments were captured,

...I love the Chinese Olympic sports team...I support England for soccer...but I don't support the Korean team...I should have my preference...but the Korean people...need me to support the Korean soccer team...but I don't want to...I expressed my interest in the English team...they don't talk to me 
anymore...and call me the Korean traitor... (Participant \#12, Focus Group Activity)

...the Chinese swimming team...in the Olympic games...is so professional...but this is not the strongest part(s) in Korea...I always expressed my love... for the Chinese swimming team...but the Korean people told me that if I want to become a Korean...I have to love the Korean team...it is not allowed to love other countries.... what is going on? (Participant \#29, Focus Group Activity)

\subsubsection{I have Adopted the South Korean Living Styles, but the Discrimination Continues}

Almost all expressed their experiences of hobbies, interests, and activities being forced on them in South Korea. Nearly three-quarters decided to listen to Korean pop music and watch Korean TV drama in order to improve their language proficiency and skill. Furthermore, many indicated that they shared some ideas and points regarding TV dramas and other shows to express their willingness to learn. However, many continued to feel bias(es) against them based on their social behaviour (Lee et al., 2017; Lee, 2007), particularly their hobbies. Two significant comments were captured,

...I don't understand why...I love to watch some old Korean TV dramas...perhaps 20 years old already...but they laughed at me...I watched some TV shows...like five years old I guess...I was being discriminated...I listened to the music...not the top stars in Korea...I was called the country girl...what's wrong with Korea?... (Participant \#13, Interview)

When the above participant shared this message, all other groupmates echoed similar experiences, such as the following,

...why can't I have my own hobbies...do I have to follow all the requirements of society? I followed the general rules...I am fine...but for my interests, hobbies, and so on...why can't I have my own ways...I watched Korean TV drama, respecting the local culture...but can I watch Chinese or American drama? Is it illegal in Korea? Even if I watch, those Korean people call me the Chinese traitor...I am so tired...(Participant \#1, Focus Group Activity)

In conclusion, although the participants strongly advocated their self-identity as Korean due to their bloodlines and family heritage, their hobbies and personal interests differed from those of the local South Korean people. Many desired to merge with and understand local cultural practices to increase their understanding (i.e. cultural assimilation) (Cui \& Zheng, 2021; Kwon, 2013). Discrimination and bias from their local peers and members of the general public discouraged their self-efficacy and self-esteem. These discouragements impacted their self-efficacy and experiences and their sense of belonging and self-identity as Korean people.

\subsection{I do not Practice South Korean Traditionals and Cultural Heritage}

Two important festivals in South Korea are Seollal (i.e., Lunar New Year's Day) and Chuseok (i.e., Korean Thanksgiving Day). Although many East Asian countries and regions celebrate these two festivals, the traditions, customs, and practices are not the same as Korean activities. For example, many participants indicated that during Lunar New Year's Day, parents and the elderly contribute pocket money to juniors in red envelopes because red represents good luck in Chinese culture. However, in South Korea, pocket money should be contributed into white envelopes. Several expressed and discussed the cultural differences with their Korean classmates and friends. All received criticism about the Chinese culture and customs. The researcher marked down the following comments,

... I want to tell my Korean classmates about the differences between pocket money...during the Lunar New Year...in China and South Korea.... Still, those Korean people laughed at me...and said the Chinese cultures and customs are weird and bad...I felt so bad...why do they need to laugh at my culture? You can laugh at me...but they cannot laugh at my country and culture...I shared with some other Korean friends 
that...they asked me to go back to China... (Participant \#9, Interview)

...I wear some special clothes for some Chinese cultural festivals on-campus...I want to show people how I like both Chinese and Korean cultures...but some students and staff on-campus... took a picture of my clothing... and posted them online for a negative discussion...some people forwarded the message back to me.... with a lot of dirty words...they called me Chinese pig... (Participant \#7, Focus Group Activity)

\subsubsection{It is my Sin to Celebrate Chinese Festivals but not South Korean Ones}

Almost all participants celebrated some Chinese festivals and customs during their university voyages in South Korea, such as the dragon boat festival with the rice dumpling and the mid-autumn festival with the moon cake. Rice dumplings and moon cakes are not available in any Korean supermarkets as these are exclusively for Chinese people. Therefore, some participants made the foods in their dorm rooms while some bought them from local Chinese supermarkets. However, when the participants brought the food to school for a meal, some Korean students laughed at their Chinese food and looked down on their traditions. The researcher captured two significant comments,

...I always eat mooncakes during the mid-autumn festival in China...the Koreans called it the Chuseok festival...Koreans eat the green onion pancake for the celebration...I don't see there are any problems...but the Korean people laughed at me because I don't eat green onion pancake...but mooncake from Chinatown...this is not a single case... a bunch of Chinese students on campus experience these discriminations and cultural scandals...every year... (Participant \#4, Focus Group Activity)

...I love Chinese mooncake because it is delicious...but Korean people call me mooncake girl and fat mooncake because of my Chinese nationality and my body...my outlook...I told the international students' services...and my professor during the lessons...the professors didn't care... and told me shut up and listened to the Korean culture...ridiculous... (Participant \#14, Focus Group Activity)

Another example is about celebrating with family members and the elderly. During the midautumn festival or the Chuseok festival in South Korea, Korean people always return to their hometown for a family reunion. However, Chinese people do not have such social and cultural behaviours. More than three-quarters of the participants indicated that their Korean classmates laughed at them because they did not have family members in South Korea. More importantly, as these participants were Korean-Chinese students who believed themselves to be South Korean people, the biases of the local South Korean people significantly harmed the self-identity and selfesteem of the participants. The researcher captured one significant comment,

...all my family members are in mainland China...I am the only one...returned back to our homeland...so I don't have family and friends there...I wish I can have my family here...and I wish I can go back to China for the celebration...but I am sad...because the Korean people...they are my people...they laughed at my nationality and self-identity...I cannot stand with these...biases... (Participant \#20, Focus Group Activity)

In short, although the participants identified themselves as Korean-Chinese with Korean family heritage, some of their social and cultural behaviours and practices had been influenced by the Chinese culture due to their early and teenage lives in mainland China. In this case, many engaged in cultural practices of Chinese festivals but not those of Korean festivals. However, the discrimination and bias from the local Korean people discouraged their self-identity, self-efficacy, and self-esteem as Korean people. As one said, “...although they laughed at me...as a Korean person...I am still a Korean...an unhappy Korean..." (Participant \#21, Interview). A sense of belonging as Korean people had been rooted in the minds of these participants (Cui \& Zheng, 2021). Based on the Sociocultural and Psychological Racism theory (Dos Santos, 2019, 2020; Lee et al., 2017; Lee, 2007), although the participants shared the same skin colour and racial characteristics as the local South Korean people, most experienced discrimination regarding all four elements of the theory: the place of origin, social behaviours, cultural characteristics, 
and spoken languages. Nevertheless, the sense of belonging of most of the participants remained unchanged due to their self-identity as Korean people (Seol \& Skrentny, 2009).

\section{Limitations and Future Research Directions}

First of all, Korean diaspora populations exist in different parts of the world. Although China has one of the highest Korean diaspora populations globally, comments and opinions from other Korean diaspora populations could be included. Therefore, future research studies may expand the focus to other overseas Korean groups in South Korea.

Second, the current study captured the comments and opinions of overseas Korean university students. Although education is one of the popular reasons why overseas Korean people come to South Korea, many overseas Korean people return to South Korea for other purposes, such as career development and marriage. Therefore, future studies of overseas Korean people could expand to cover those with purposes other than education.

Third, the current study employed the Sociocultural and Psychological Racism theory (Dos Santos, 2019, 2020; Lee et al., 2017; Lee, 2007) as the theoretical framework, and thus mainly focused on the sociological factors of overseas Korean people. Future research could adopt other theories and research perspectives, such as philosophical and ethical perspectives, to explore the same questions.

\section{Implications and Conclusion}

The results of this study will contribute to different channels. First, the overseas Korean population is a special and unique group that has developed over the past century. Although many overseas Korean groups have continued to educate their next generations in the Korean language, culture, and behaviours, host cultures and behaviours have influenced the backgrounds of the next generations. Although the South Korean government has established immigration plans for overseas Korean people to return, many returned Korean people continue to face difficulties and challenges. Therefore, the results of this study will become a blueprint for government agencies, non-profit organisations, and policymakers to reform current social and political policies and plans.

Second, university leaders and department heads can use this study's findings to polish their services for international students, including but not limited to overseas Korean students. As overseas Korean people will eventually become one of the strongest workforces in Korean society, career development and further services are greatly needed.

In conclusion, due to political and social issues, members of the Korean diaspora have lived in different parts of the world for a century. Although many share the same Korean social and cultural sense of belonging, many continue to face difficulties and challenges due to their place of origin, social behaviours, cultural characteristics, and spoken languages. Korean society should continue developing plans to deal with discrimination and racist biases to satisfy the needs of international expats. Otherwise, international professionals may leave Korea for other countries and regions with better international services.

\section{Acknowledgement}

This study was supported by Woosong University Academic Research Funding 2022.

\section{References}

Campion, L. L., \& Wang, C. X. (2019). Collectivism and Individualism: the Differentiation of Leadership. TechTrends, 63(3), 353-356. https://doi.org/10.1007/s11528-019-00399-x

Castillo Arredondo, M. I., Rodríguez Zapatero, M. I., Pérez Naranjo, L. M., \& López-Guzmán, T. (2018). Motivations of educational tourists in non-English-speaking countries: the role of languages. Journal of Travel E Tourism Marketing, 35(4), 437-448. https://doi.org/10.1080/10548408.2017.1358238 
Chosonjok. (2021). National Ethics Affairs Commission of the People's Republic of China. https://web.archive.org/web/20200317000630/http://www.seac.gov.cn/seac/ztzl/cxz/gk.shtml

Chung, E. A. (2020). Creating hierarchies of noncitizens: race, gender, and visa categories in South Korea. Journal of Ethnic and Migration Studies, 46(12), 2497-2514. https://doi.org/10.1080/1369183X.2018.1561061

Creswell, J. (2014). Research design: Qualitative, quantitative, and mixed methods approaches (4th ed.). Sage.

Cui, H., \& Zheng, Y. (2021). Ethnicity is in the blood, not in the language: exploring Korean-Chinese bilingual families' multilingual planning. Journal of Multilingual and Multicultural Development, 1-18. https://doi.org/10.108o/o1434632.2020.186848o

Dos Santos, L. M. (2020). Becoming university language teachers in South Korea: The application of the interpretative phenomenological analysis and social cognitive career theory. Journal of Education and ELearning Research, 7(3), 250-257. https://doi.org/10.20448/journal.509.2020.73.250.257

Dos Santos, L. M. (2019). Experiences and expectations of international students at historically black colleges and universities: An interpretative phenomenological analysis. Education Sciences, 9(3), 189. https://doi.org/10.3390/educscig030189

Dos Santos, L. M. (2020a). Stress, burnout, and turnover issues of Black expatriate education professionals in South Korea: Social biases, discrimination, and workplace bullying. International Journal of Environmental Research and Public Health, 17(11), 3851. https://doi.org/10.3390/ijerph17113851

Dos Santos, L. M. (2020b). The challenging experiences of international students in South Korea: The neo-racism perspective. Universal Journal of Educational Research, 8(12B), 8102-8109. https://doi.org/10.13189/ujer.2020 .082612

Dos Santos, L. M. (2021). The relationship between social stigma and Brexit of European teachers in the United Kingdom: The inquiry of sociocultural and psychological racism. Journal of Educational and Social Research, 11(6), 10-21. https://doi.org/10.36941/jesr-2021-0124

Fang, G. (2009). Challenges of discourses on "Model Minority" and "South Korean Wind" for ethnic Koreans' schooling in northeast China. Diaspora, Indigenous, and Minority Education, 3(2), 119-130. https://doi.org/10.1080/15595690802584133

Gao, F. (2010). Learning Korean language in China: motivations and strategies of non-Koreans. International Journal of Bilingual Education and Bilingualism, 13(3), 273-284. https://doi.org/10.1080/13670050903006929

Gao, F. (2012). Imagined identity of ethnic Koreans and its implication for bilingual education in China. International Journal of Bilingual Education and Bilingualism, 15(3), 343-353. https://doi.org/10.108o/13670050.2011.636146

Giorgi, A. (1985). Phenomenology and psychological research. Duquesne University Press.

Han, C. M. (2017). Individualism, collectivism, and consumer animosity in emerging Asia: evidence from Korea. Journal of Consumer Marketing, 34(4), 359-370. https://doi.org/10.1108/JCM-o9-2016-1937

Hong, J. (2019). Effects of ethnic identity on the relationship between mental health and perceived discrimination among ethnic return migrants: The case of Korean Chinese return-migrated to South Korea. Journal of Immigrant and Minority Health, 21(3), 522-532. https://doi.org/10.1007/s10903-018-0775-9

Hong, J. S., Kim, D. H., \& Piquero, A. R. (2017). Assessing the links between punitive parenting, peer deviance, social isolation and bullying perpetration and victimization in South Korean adolescents. Child Abuse $\mathcal{E}$ Neglect, 73, 63-7o. https://doi.org/10.1016/j.chiabu.2017.09.017

Kim, H. (2015). Migrant workers in south korean society. In Democratic Governance in Northeast Asia (pp. 51-69). Palgrave Macmillan UK. https://doi.org/10.1057/9781137550453_3

Korea immigration service statistics 2017. (2017). https://m.korea.kr/expertWeb/resources/files/data/document file/2017/2017 출 입 국 ·외 국 인 정 책 통 계 연 보.pdf

Kwon, Y. (2013). The sociocultural adjustment of Chinese graduate students at Korean universities: A qualitative study. International Journal of Intercultural Relations, 37(5), 536-549. https://doi.org/10.1016/j.ijintrel .2013 .06 .004

Lee, H. (1997). The employment of foreign workers in Korea. International Sociology, 12(3), 353-371. https://doi.org/10.1177/026858097012003005

Lee, J. J. (2007). Bottom line-Neo-racism toward international students. About Campus: Enriching the Student Learning Experience, 11(6), 28-30. https://doi.org/10.1002/abc.194

Lee, J., Jon, J., \& Byun, K. (2017). Neo-racism and neo-nationalism within East Asia. Journal of Studies in International Education, 21(2), 136-155. https://doi.org/10.1177/1028315316669903

Lee, S., \& Chien, Y.-C. (2017). The making of 'skilled' overseas Koreans: Transformation of visa policies for coethnic migrants in South Korea. Journal of Ethnic and Migration Studies, 43(13), 2193-2210. https://doi.org/10.1080/1369183X.2016.1273102

Li, J.-B., T. Vazsonyi, A., \& Dou, K. (2018). Is individualism-collectivism associated with self-control? Evidence from Chinese and U.S. samples. PLOS ONE, 13(12), e0208541. https://doi.org/10.1371/journal.pone.0208541 
Liao, H.-C., \& Yang, C.-C. (2012). Teaching Practice and Cultural Difference of an English as Foreign Language Classroom in Taiwan. English Language Teaching, 5(11). https://doi.org/10.5539/elt.v5nup151

Lyu, H. (2020). The future for ethnic Korean Minority education in China: A challenge for teacher education. In W. Tao \& I. Liyanage (Eds.), Multilingual Education Yearbook 2020 (pp. 113-128). Springer International Publishing. https://doi.org/10.1007/978-3-030-41211-1

Merriam, S. B. (2009). Qualitative research: A guide to design and implementation. Jossey Bass.

Min, S. (2020). Dynamical network analysis of the South Korean dialects compared to traditional dialect classification. Journal of the Korean Physical Society, 77(4), 303-311. https://doi.org/10.3938/jkps.77.303

Park, M. Y. (2020). 'I want to learn Seoul speech!': Language ideologies and practices among rural marriagemigrants in South Korea. International Journal of Bilingual Education and Bilingualism, 23(2), 227-240. https://doi.org/10.108o/13670050.2017.1351419

Seol, D., \& Skrentny, J. (2009). Ethnic return migration and hierarchical nationhood. Ethnicities, 9(2), 147-174. https://doi.org/10.1177/1468796808099901

Song, H., \& Bae, S. Y. (2018). Understanding the travel motivation and patterns of international students in Korea: using the theory of travel career pattern. Asia Pacific Journal of Tourism Research, 23(2), 133-145. https://doi.org/10.108o/10941665.2017.1410193

Strauss, A., \& Corbin, J. M. (1990). Basics of qualitative research: Grounded theory procedures and techniques. Sage.

Sun, H., Steinkrauss, R., Tendeiro, J., \& De Bot, K. (2016). Individual differences in very young children's English acquisition in China: Internal and external factors. Bilingualism: Language and Cognition, 19(03), 550-566. https://doi.org/10.1017/S1366728915000243

Tang, K. H., \& Dos Santos, L. M. (2017). A brief discussion and application of interpretative phenomenological analysis in the field of health science and public health. International Journal of Learning and Development, 7(3), 123-132. https://doi.org/10.5296/ijld.v7i3.11494

Williams, D. (1999). Race, socioeconomic status, and health: The added effects of racism and discrimination. Annals of the New York Academy of Sciences, 896(1), 173-188. https://doi.org/10.111//.17496632.1999.tbo8114.x

Zhao, Z. (2010). China's ethnic dilemma: Ethnic minority education. Chinese Education \& Society, 43(1), 3-11. https://doi.org/10.2753/CED1061-1932430100 